\title{
KEANEKARAGAMAN JENIS POHON DI HUTAN LINDUNG GUNUNG SAHENDARUMAN, KABUPATEN KEPULAUAN SANGIHE
}

\section{TREE SPECIES BIODIVERSITY OF THE MOUNT SAHENDARUMAN PROTECTION FORES IN SANGIHE ISLANDS REGENCY}

\author{
Reynold P. Kainde \\ Jurusan Budidaya Pertanian, Fakultas Peranian UNSRAT Manado _ 95115
}

\begin{abstract}
This research was carried out in the Mount of Sahendaruman Protection Forest from February to May 2006, aiming to find out information tree spesies biodiversity. The method was exploration using transects of $20 \mathrm{~m}$ wide from the mountain top divided in 8 directions. Result showed that there were 70 tree species from 32 families belong to Magnoliopsida (dicotyl) and division of Magnoliophyta (flower plant). There were 7 tree species in which member of Euphorbiaceae, Lauraceae dan Rubiaceae. Five tree species were member of Apocynaceae. Four tree species were member of Meliaceae. Family of Actinidaceae, Burseraceae, Guttiferae, Monimiaceae had three species each. The following family namely Anacardiaceae, Araliaceae, Myristicaceae, Myrtaceae, Theaceae donated two species each. Each family of Aquifoliaceae, Bignoniaceae, Celastraceae, Combretaceae, Combretaceae, Ealeocarpaceae, Ebenaceae, Fagaceae, Flacour tiaceae, Gesperiaceae, Mimosaceae, Moraceae, Ochnaceae, Rutaceae, Sapindaceae, Sapotaceae, Saxifragaceae, Staphyleaceae accounted one species.
\end{abstract}

Keywords : Tree Species, Magnoliophyta, Biodiversity

\begin{abstract}
ABSTRAK
Penelitian ini dilaksanakan di Hutan Lindung Gunung Sahendaruman Kebupaten Kepulauan Sangihe, yang berlangsung mulai bulan Februari - Mei 2006 dengan tujuan untuk mendapatkan informasi tentang keanekaragaman jenis pohon di Hutan Lindung Gunung Sahendaruman. Penelitian ini menggunakan metode eksplorasi dengan menggunakan jalur pengamatan. Lebar jalur $20 \mathrm{~m}$ dan arah jalur dari puncak ke arah bawah dan dibagi menjadi 8 arah. Hasil yang diperoleh menunjukan bahwa terdapat 70 jenis pohon dari 32 famili yang keseluruhan jenis-jenis pohon tersebut adalah kelas Magnoliopsida (tumbuhan dikotil) dan divisi Magnoliophyta (tumbuhan berbunga) Kelas Magnoliopsida (tumbuhan dikotil). Terdapat 7 jenis pohon yang merupakan anggota Euphorbiaceae Lauraceae dan Rubiaceae, 5 jenis pohon anggota Apocynaceae, 4 jenis pohon anggota of Meliaceae, 3 jenis pohon anggota of Actinidaceae, Burseraceae, Guttiferae, Monimiaceae, 2 jenis pohon anggota Anacardiaceae, Araliaceae, Myristicaceae, Myrtaceae, Theaceae dan yang memiliki jumlah jenis paling sedikit adalah famili Aquifoliaceae, Bignoniaceae, Celastraceae, Combretaceae, Combretaceae, Ealeocarpaceae, Ebenaceae, Fagaceae, Flacour tiaceae, Gesperiaceae, Mimosaceae, Moraceae, Ochnaceae, Rutaceae, Sapindaceae, Sapotaceae, Saxifragaceae, Staphyleaceae, Sterculiaceae yang masing-masing family tersebut diperoleh satu jenis pohon.

Kata kunci : Tree spesies pohon, magnoliophyta, biodiversity
\end{abstract}

Eugenia Volume 17 No. 1 April 2011 


\section{PENDAHULUAN}

Hutan Lindung Gunung Sahendaruman (HLGS) terletak di Kabupaten Kepulauan Sangihe Propinsi Sulawesi Utara. Sangihe merupakan salah satu pulau besar dalam kelompok kepulauan Sangihe dan Talaud yang terbentang diantara ujung utara pulau Sulawesi dan ujung selatan pulau Mindanau di Philipina. HLGS ditetapkan sebagai hutan lindung dengan luas 3.549 ha melalui SK MenHutBun No.452/KPTS-II/1999, tanggal 17 Juni 1999. HLGS merupakan pusat dari keanekaragaman hayati Pulau Sangihe, karena memiliki beranekaragam flora dan fauna endemik yang kehidupannya tergantung pada hutan asli yang tersisa (Anonimous, 2001).

Secara astronomis HLGS terletak pada $03^{\circ} 30.99 \mathrm{~N}$ dan $125^{\circ} 31.25 \mathrm{E}$ dengan ketinggian 1.031 meter diatas permukaan laut. Kawasan Sahendaruman meliputi 5 kecamatan yaitu Tamako, Manganitu, Manganitu Selatan, Tabukan tengah dan Tabukan selatan, sebanyak 30 desa yang tersebar di lima kecamatan tersebut bersentuhan langsung dengan kawasan hutan ini. Bahasa utama yang digunakan oleh masyarakat setempat adalah Bahasa Sangir, selain itu juga masyarakat menggunakan Bahasa Manado dan bahasa dari daerah lain yang dibawa oleh pendatang (Anonimous, 2001).

Lahan berhutan yang saat ini hanya terdapat dipuncak jajaran Gunung Sahendaruman memiliki potensi wisata seperti air terjun, tempattempat keramat, perlindungan satwa endemik seperti kus-kus beruang (Ailurops ursinus melanotis) dan habitat burung-burung khas Sangihe. Peran penting lainnya adalah mensuplai air bagi penduduk dan melindungi sumber daya air di Sungai Ulung Peliang tempat beroprasinya PLTM (Pembangkit Listrik Tenaga Mikro-Hidro) yang memasok tenaga listrik bagi desa-desa selatan Sangihe.

Degaradasi sumberdaya hutan yang terjadi karena hutan juga dimanfaatkan untuk memenuhi kebutuhan masyarakat secara langsung seperti pengambilan hasil hutan (seperti : woka, rotan, bambu, bahan untuk obat-obatan, kayu untuk perabotan rumah, konstruksi perumahan dan perahu), perladangan berpindah, pembangunan jalan antar kampung dan kepariwisataan.

Sumberdaya hutan yang tersisa perlu dilestarikan dan dikelola dengan campur tangan manusia, karena semakin sempitnya suatu kawasan akan semakin rawan terhadap kehilangan spesies dan mengakibatkan kualitas habitat terdegradasi. Konservasi jenis tumbuhan merupakan sebagian dari usaha untuk melindungi jenis-jenis tumbuhan asli hutan alam terutama yang mulai langka (Zain, 1998), untuk itu diperlukan data dan informasi mengenai keadaan areal hutan meliputi komposisi jenis dari vegetasi yang tumbuh didalamnya (Husc, 1987). Brooks (2001) dalam Indrawan, dkk. (2007) mengatakan bahwa bila data rinci yang dibutuhkan dalam menggambarkan suatu komunitas tidak tersedia maka spesies tertentu dapat digunakan sebagai indikator keanekaragaman hayati. Menururt Saetersdal (2003) dalam Indrawan, dkk. (2007) bahwa dalam kawasan dengan keragaman spesies tumbuhan berbunga yang tinggi memiliki keragaman jenis lumut, siput, laba-laba dan jamur yang tinggi pula. Selanjutnya Ricketts (1999) dalam Indrawan, dkk. (2007) mengatakan bahwa keragaman jenis tumbuhan dan burung seringkali merupakan indikator yang baik bagi keragaman komunitas. Dengan demikian keragaman pohon yang tinggi dapat menciptakan habitat yang sesuai dan relung-relung untuk berbagai jenis organisme dan terciptanya jaringjaring makanan, siklus hara dan siklus energi yang efisien untuk perkembangan dan kestabilan yang dinamis dari suatu ekosistem.

Penelitian ini bertujuan untuk mengetahui jenis tumbuhan berhabitus pohon dan menyajikannya dalam bentuk daftar tumbuhan sebagai data dasar khusus untuk pohon yang ada di Hutan Lindung Gunung Sahendaruman Kabupaten Kepulauan Sangihe.

\section{METODE PENELITIAN}

Penelitian ini dilaksanakan di Hutan Lindung Gunung Sahendaruman Kabupaten Kepulauan Sangihe. Identifikasi jenis dilaksanakan di Herbarium Wallaceana Fakultas Pertanian Universitas Sam Ratulangi dan Herbarium 
Wanariset, di Semboja, Kaltim pada bulan Februari sampai bulan Mei 2006.

\section{Bahan Dan Alat}

Bahan dan alat yang digunakan adalah spritus, kantong plastik, karton, kertas koran, buku koleksi, label gantung, peta HLGS, GPS, altimeter, kompas, toropong, tali, loupe, mistar, gunting stek, meteran, alat tulis menulis, buku kunci identifikasi (Corner, 1998., Whitmore, 1972, Keßler,1999)

\section{Metode Penelitian}

Penelitian ini menggunakan metode eksplorasi dimana eksplorasi tumbuhan dengan menggunakan jalur pengamatan dengan lebar 20 $\mathrm{m}$, arah jalur dari puncak kearah bawah berdasarkan arah mata angin yaitu jalur bagian utara $\left(0^{\circ}\right)$, timur laut $\left(45^{\circ}\right)$, timur $\left(90^{\circ}\right)$, tenggara $\left(135^{\circ}\right)$, selatan $\left(180^{\circ}\right)$, barat daya $\left(225^{\circ}\right)$, barat $\left(270^{\circ}\right)$ dan barat laut $\left(315^{\circ}\right)$.

\section{Prosedur Kerja}

1) Persiapan bahan dan alat 2) Survey awal dilokasi penelitian untuk penentuan 8 jalur pengamatan berdasarkan arah mata angin yaitu utara, timur laut, timur, tenggara, selatan, barat daya, barat dan barat laut. 3) Pengamatan dilakukan terhadap karakteristik morfologi pohon yang berdiameter $20 \mathrm{~cm}$ keatas dan mengumpulkan spesimen sebanyak 3 eksemplar untuk setiap jenis tanaman, membuat foto dan memberi etiket gantung bertuliskan nomor koleksi masing-masing spesimen..4) Tanaman diselipkan dalam lipatan kertas koran lalu dimasukkan kedalam kantong plastik yang terikat selanjutnya dibasahi dengan spritus. 5) Spesimen dirapikan dan dikeringkan dengan menggunakan oven pengering selama 3 hari. Satu spesimen yang masih segar dipakai untuk melengkapi deskripsi yang dibuat di lapangan.
Spesimen yang sudah kering dimounting kemudian dideterminasi di Herbarium Wallaceana Fakultas Pertanian Universitas Sam Ratulangi dan Herbarium Wanariset, di Semboja, Kaltim. 6) Spesimen yang sudah dimounting diberi label herbarium yang berisi tentang informasi lembaga pemilik, nama lokal, nama botani, nama orang yang mendeterminasi, lokasi pengambilan sampel dan gambaran umum tumbuhan secara umum.

\section{HASIL DAN PEMBAHASAN}

Berdasarkan spesimen yang diperoleh dari hasil eksplorasi pohon yang dilaksanakan di Hutan Lindung Gunung Sahendaruman, telah berhasil diidentifikasi 70 spesies, 58 genus, 32 famili, 18 ordo, 5 sub kelas dan semuanya kelas Magnoliopsida (tumbuhan dikotil), divisi Magnoliophyta (tumbuhan berbunga). Hasil identifikasi dan determinasi dapat dilihat pada tabel 1

Berdasarkan tabel 1. maka diketahui yang memiliki keanekaragaman jenis pohon yang paling tinggi adalah Euphorbiaceae, Lauraceae dan Rubiaceae dimana ada 7 spesies anggota famili tersebut. Selanjutnya, Apocynaceae 5 spsies, Meliaceae 4 spesies, Actinidaceae, Burseraceae, Guttiferae, Monimiaceae- masing-masing 3 spesies, Anacardiaceae, Araliaceae, Myristicaceae, Myrtaceae, Theaceae masing-masing 2 spesies dan yang paling sedikiit yaitu Aquifoliaceae, Bignoniaceae, Celastraceae, Combretaceae, Elaeocarpaceae, Ebenaceae, Fagaceae, Flacourtiaceae, Gesneriaceae, Mimosaceae, Moraceae, Ochnaceae, Rutaceae, Sapindaceae, Sapotaceae, Saxifragaceae, Staphyleaceae, Sterculiaceae masing-masing tersebut 1 spesies. Keseluruhan jenis-jenis pohon tersebut dari divisi Magnoliophyta (tumbuhan berbunga), kelas Magnoliopsida (tumbuhan dikotil) yang terbagi dalam 5 sub kelas selanjutnya ketingkat taxon yang lebih rendah yaitu 18 ordo kemudian 32 famili dan 70 spesies pohon yang ditemukan. Hubungan antar taxon tersebut dapat dilihat pada diagram klasifikasi 70 jenis pohon. 
Tabel 1. Jenis-Jenis Pohon di Hutan Lindung Gunung Sahendaruman Table 1 (Tree Species of Sahendaruman Protection Forest)

\begin{tabular}{|c|c|c|c|}
\hline No. & No. Koleksi & Famili & Nama Botani \\
\hline 1. & $\mathrm{EH}-53$ & Apocynaceae & Alstonia macrophylla \\
\hline 2. & EH-64 & & Alstonia stapfii \\
\hline 3. & $\mathrm{EH}-47$ & & Kopsia sp. \\
\hline 4. & $\mathrm{EH}-24$ & & Tabernaemontana sp. \\
\hline 5. & EH-67 & & Ochrocia glomerata \\
\hline 6. & $\mathrm{EH}-75$ & Rubiaceae & Aidia sp \\
\hline 7. & $\mathrm{EH}-13$ & & Lucinaea sp. \\
\hline 8. & $\mathrm{EH}-33$ & & Nauclea sp. \\
\hline 9. & $\mathrm{EH}-71$ & & Pertusadina eurhyncha \\
\hline 10. & $\mathrm{EH}-11$ & & Plectronia sp. \\
\hline 11. & $\mathrm{EH}-14$ & & Timonius celebicus \\
\hline 12. & $\mathrm{EH}-26$ & & Wendlandia burkillii \\
\hline 13. & $\mathrm{EH}-48$ & Bignoniaceae & Deplanchea sp. \\
\hline 14. & EH-31 & Gesneriaceae & Cyrtandra sp. \\
\hline 15. & $\mathrm{EH}-58$ & Ebenaceae & Diospyros sp. \\
\hline 16. & $\mathrm{EH}-32$ & Sapotaceae & Palaqium sp. \\
\hline 17. & $\mathrm{EH}-74$ & Flacourtiaceae & Homalium foetidum \\
\hline 18. & $\mathrm{EH}-01$ & & Elaeocarpus sp \\
\hline 19. & $\mathrm{EH}-05$ & & Sterculia insularis \\
\hline 20. & $\mathrm{EH}-08$ & Actinidiaceae & Saurauia sp. (A) \\
\hline 21. & $\mathrm{EH}-50$ & & Saurauia sp. (B) \\
\hline 22. & EH-54 & & Saurauia sp. (C) \\
\hline 23. & $\mathrm{EH}-42$ & Gutiferae & Calophyllum Sp \\
\hline 24. & $\mathrm{EH}-25$ & Ochnaceae & Schurmansia elegans. \\
\hline 25. & $\mathrm{EH}-02$ & Theaceae & Adinandra sp. \\
\hline 26. & $\mathrm{EH} 16$ & & Gordonia sp. \\
\hline 27. & $\mathrm{EH} 22$ & Moraceae & Ficus sp. \\
\hline 28. & EH66 & Fagaceae & Quercus sp. \\
\hline 29. & $\mathrm{EH} 23$ & & Garcinia sp. (A) \\
\hline 30. & $\mathrm{EH} 36$ & & Garcinia sp. (B) \\
\hline 31. & EH18 & Lauraceae & Cryptocarya sp. (A) \\
\hline 32. & $\mathrm{EH} 49$ & & Cryptocarya sp. (B) \\
\hline 33. & EH61 & & Cryptocarya sp. (C) \\
\hline 34. & $\mathrm{EH} 10$ & & Litsea sp. (A) \\
\hline 35. & EH39 & & Litsea sp. (B) \\
\hline 36. & $\mathrm{EH} 60$ & & Litsea sp. (C) \\
\hline 37. & EH41 & & Lindera sp. \\
\hline 38. & EH37 & Monimiaceae & Kibara sp. (A) \\
\hline 39. & EH63 & & Kibara sp. (B) \\
\hline 40. & $\mathrm{EH} 70$ & & Kibara sp. (C) \\
\hline 41. & $\mathrm{EH} 28$ & Myristicaceae & Endocomia macroccoma \\
\hline 42. & $\mathrm{EH} 77$ & & Knema sp. \\
\hline 43. & EH57 & Araliaceae & Grastonia sp. \\
\hline 44. & $\mathrm{EH} 43$ & & Scefflera sp. \\
\hline
\end{tabular}


Lanjutan Tabel 1. Jenis-Jenis Pohon di Hutan Lindung Gunung Sahendaruman

\begin{tabular}{|c|c|c|c|}
\hline 45. & EH06 & Aquifoliaceae & llex sp. \\
\hline 46. & EH79 & Celastraceae & Euonymus sp. \\
\hline 47. & $\mathrm{EH} 07$ & Euphorbiaceae & Acalypha sp. \\
\hline 48. & $\mathrm{EH} 29$ & & Breynia cernua \\
\hline 49. & $\mathrm{EH} 46$ & Euphorbiaceae & Codiaeum sp. \\
\hline 50. & $\mathrm{EH} 73$ & & Drypetes neglecta \\
\hline 51. & $\mathrm{EH} 44$ & & Glochidion sp. \\
\hline 52. & $\mathrm{EH} 45$ & & Homalanthus populneus \\
\hline 53. & EH35 & & Macaranga sp. \\
\hline 54. & EH69 & Mimosaceae & Albizia sp. \\
\hline 55. & EH56 & Combretaceae & Terminalia sp. \\
\hline 56. & $\mathrm{EH} 12$ & Myrtaceae & Eugenia sp. \\
\hline 57. & $\mathrm{EH} 17$ & Saxifragaceae & Polyosma sp. \\
\hline 58. & $\mathrm{EH} 19$ & Anacardiaceae & Buchanania sp. \\
\hline 59. & EH52 & & Melanochyla sp. \\
\hline 60. & $\mathrm{EH} 15$ & Burseraceae & Canarium asperum \\
\hline 61. & EH68 & & Canarium sp. \\
\hline 62. & EH55 & & Daciyodes sp. \\
\hline 63. & $\mathrm{EH} 30$ & Meliaceae & Aglaia sp. (A) \\
\hline 64. & EH76 & & Aglaia Sp. (B) \\
\hline 65. & EH38 & & Dysoxylum Sp \\
\hline 66. & EH34 & & Vavaea Sp. \\
\hline 67. & EH65 & & Tristania Sp. \\
\hline 68. & $\mathrm{EH} 20$ & Rutaceae & Xanthoxylum Sp. \\
\hline 69 & $\mathrm{EH} 72$ & Sapindaceae & Guioa Sp. \\
\hline 70. & $\mathrm{EH} 40$ & Staphyleaceae & Turpinia Sp. \\
\hline
\end{tabular}


Diagram klasifikasi 70 jenis pohon dihutan lindung Gunung Sahendaruman




Lanjutan Diagram klasifikasi 70 jenis pohon dihutan lindung Gunung Sahendaruman

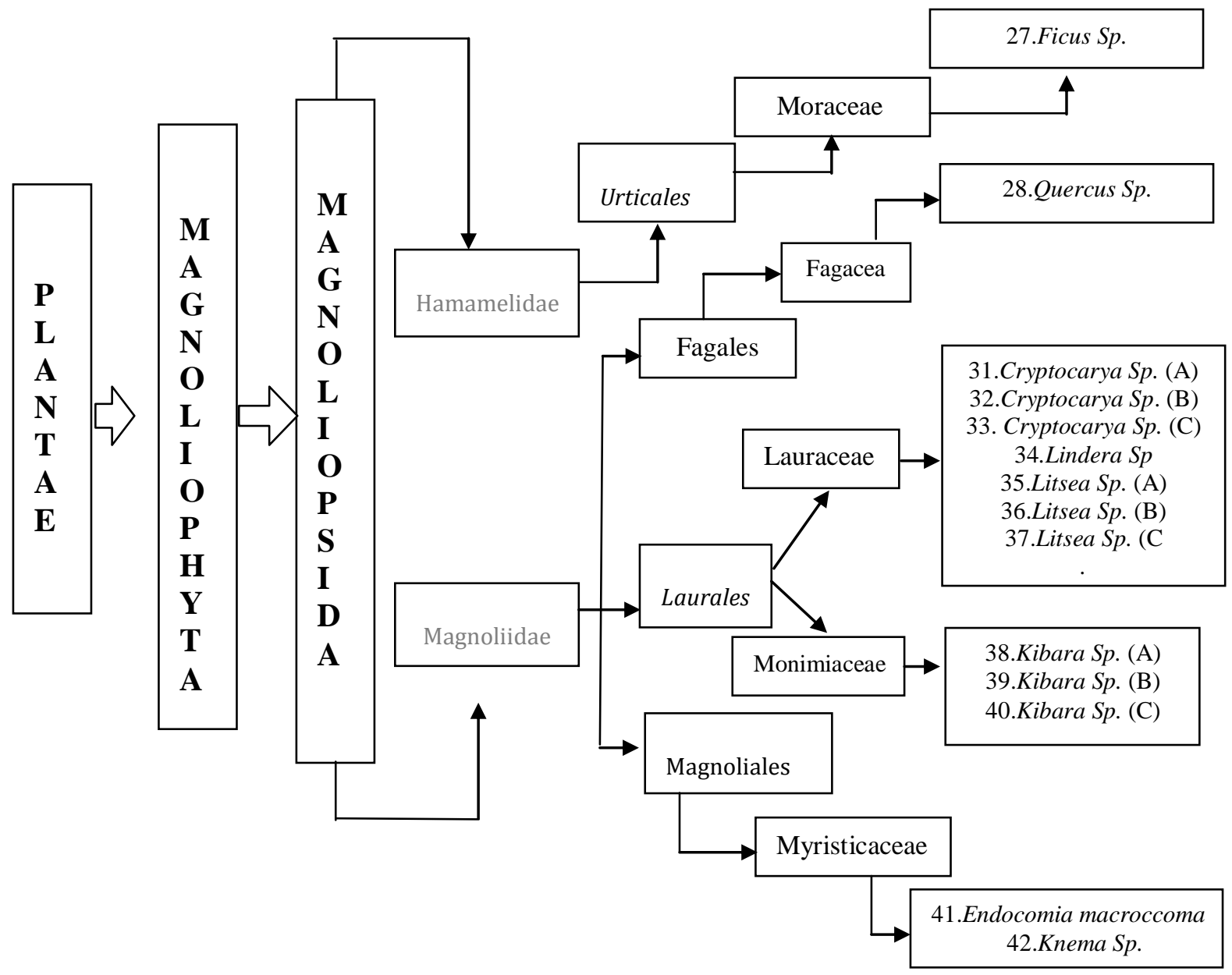


Lanjutan Diagram klasifikasi 70 jenis pohon dihutan lindung Gunung Sahendaruman

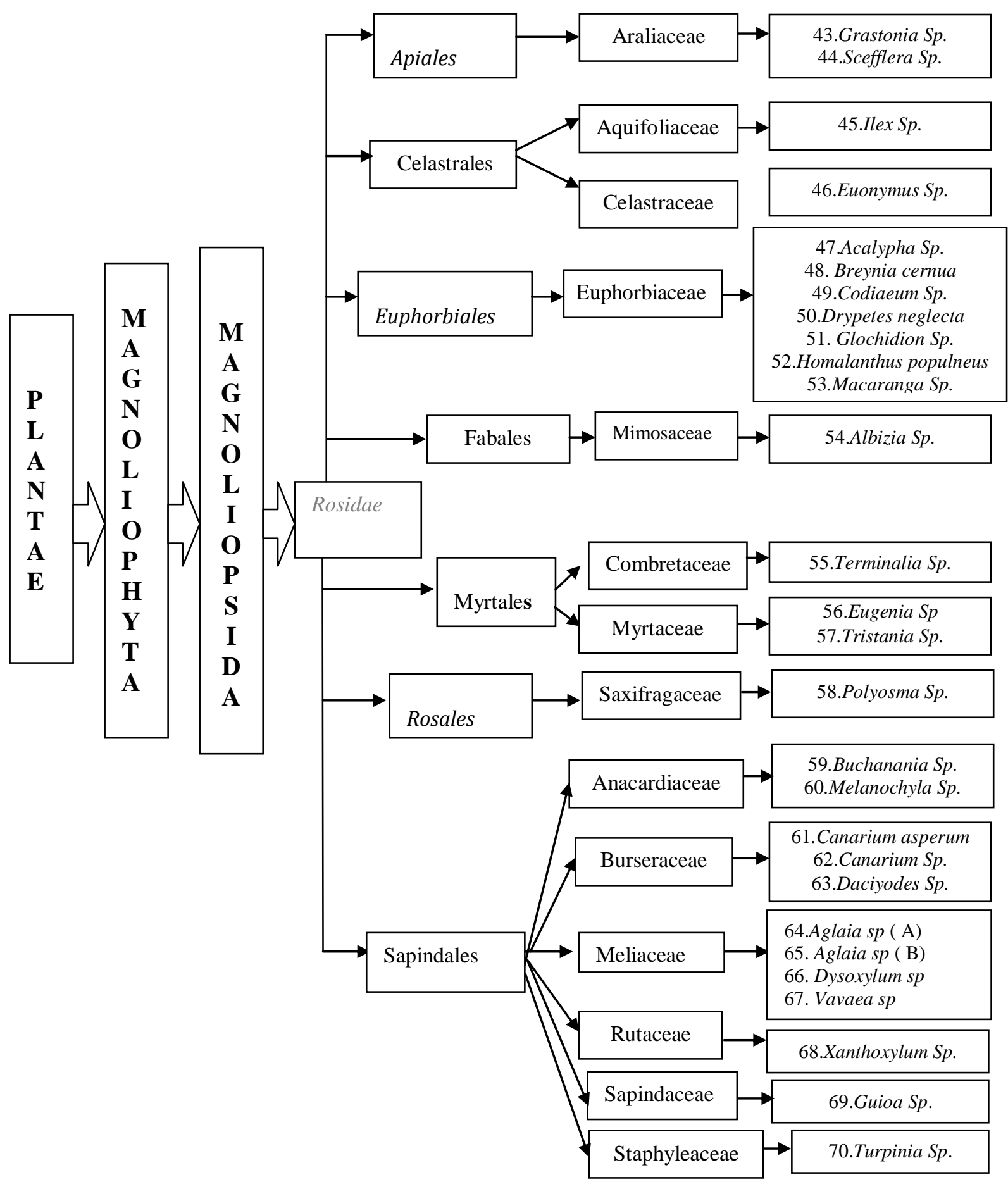




\section{KESIMPULAN}

Setidaknya di Hutan Lindung Gunung Sahendaruman terdapat 70 spesies pohon dari 32 famili yang semuanya termasuk dalam kelas Magnoliopsida (tumbuhan dikotil), divisi Magnoliophyta (tumbuhan berbunga).

Jika dilihat dari jumlah jenis yang diperoleh famili Euphorbiaceae, Lauraceae dan Rubiaceae memiliki keanekaragaman jenis yang paling tinggi yaitu berjumlah 7 jenis pohon, sedangkan yang memiliki keanekaragaman jenis terendah adalah famili Aquifoliaceae, Bignoniaceae, Celastraceae, Combretaceae, Ealeocarpaceae, Ebenaceae, Fagaceae, Flacourtiaceae, Gesneriaceae, mimosaceae, Moraceae, Ochnaceae, Rutaceae, Sapindaceae, Sapotaceae, Saxifragaceae, Staphyliaceae dan Sterculiaceae yang masingmasing famili hanya diperoleh 1 jenis pohon saja.

\section{DAFTAR PUSTAKA}

Anonimous. 2001. Konservasi Hutan Kunci di Kepulauan Sangihe - Talaud Indonesia. Bird Life International Indonesia Programme.
Corner, E.J.H. 1988. Wayside Trees Of Malaya, In Two Volumes. United Selangor Press. Kuala Lumpur, Malaya.

Husc, B. 1987. Perencanaan Inventarisasi Hutan. Universitas Indonesia. Jakarta.

Indrawan,M., R.B Primack,., J.Supriatna. (2007) Biologi Konservasi (Ed II). Yayasan Obor Indonesia. Jakarta.

Keßler, P.A. dan Sidiyasa.K., 1999. Pohon-Pohon Hutan Kalimantan Timur. MOFECTropenbos. Balikpapan, Kalimantan

Van Steenis, C.G.G.J. 1988. Flora. PT. Paradnya Paramita. Jakarta.

Whitmore, T.C, 1972. Tree Flora of Malaya. Forest Departmen. Kuala Lumpur, Malaysia.

Zain, A. S. 1998. Kamus Kehutanan. Rineka Cipta. Jakarta. 